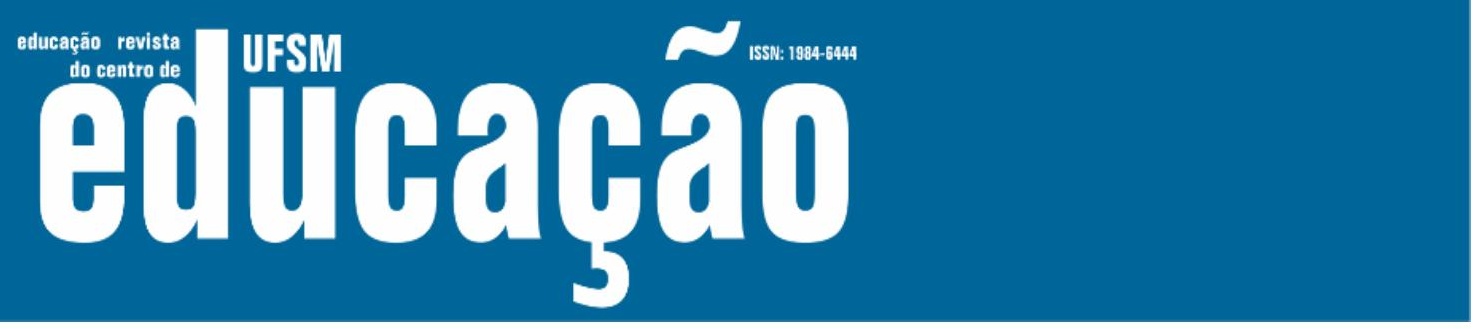

ISSN: 1984-6444 | http://dx.doi.org/10.5902/1984644445787

\title{
O papel das adaptações e transcrições braille na contextualização do ensino de química: levantamento sócioestatístico do centro de apoio pedagógico ao deficiente visual do Estado do Amapá
}

The role of adaptations and braille transcriptions in the context of teaching chemistry: socio-statistical survey of the pedagogical support center for the visually impaired in the state of Amapá

Agerdânio Andrade de Souza

Professor doutor da Universidade Federal do Amapá, Macapá, Amapá, Brasil. as.unifap@gmail.com - orcid.org/0000-0002-9984-8567

Ana Paula da Silva Freire

Professora na Escola Estadual de Ensino Integral Elizabeth Picanço Esteves - Secretaria de Educação do Estado do Amapá. Macapá, Amapá, Brasil.

freireana1990@gmail.com - orcid.org/0000-0001-7358-9045

Oberdan José Teixeira Chaves

Professor do Centro de Apoio Pedagógico ao Deficiente Visual - Secretaria de educação do estado do Amapá. Macapá, Amapá, Brasil.

oberdanc@hotmail.com - orcid.org/0000-0002-4464-2297

Solange Rodrigues da Silva

Professora doutora da Universidade Federal do Amapá, Macapá, Amapá, Brasil.

so_ufms@hotmail.com - https://orcid.org/0000-0002-2231-3783

Recebido em 07 de janeiro de 2020

Aprovado em 09 de janeiro de 2020

Publicado em 30 de dezembro de 2021

\section{RESUMO}

A presente pesquisa experimental traz a temática de inclusão dos Deficientes Visuais no ensino regular. Objetivando analisar o processo de inclusão de alunos com deficiência visual, suplementados com transcrições braille e material didático adaptado na disciplina de química, produzidos pelo Centro de Apoio Pedagógico da Pessoa com Deficiência Visual do Amapá, Brasil, no último quinquênio, bem como refletir a respeito do processo educativo desses indivíduos, levando em consideração a compreensão de conceitos químicos nos diferentes Níveis do Ensino. Metodologicamente o estudo pauta-se na Teoria Gestaltista, onde não se pode conhecer o todo através das partes, e sim as partes por meio do conjunto de ações realizadas. Dentre os procedimentos metodológicos, destacam-se a catalogação do atendimento educacional voltados aos alunos DVs, quantificações 


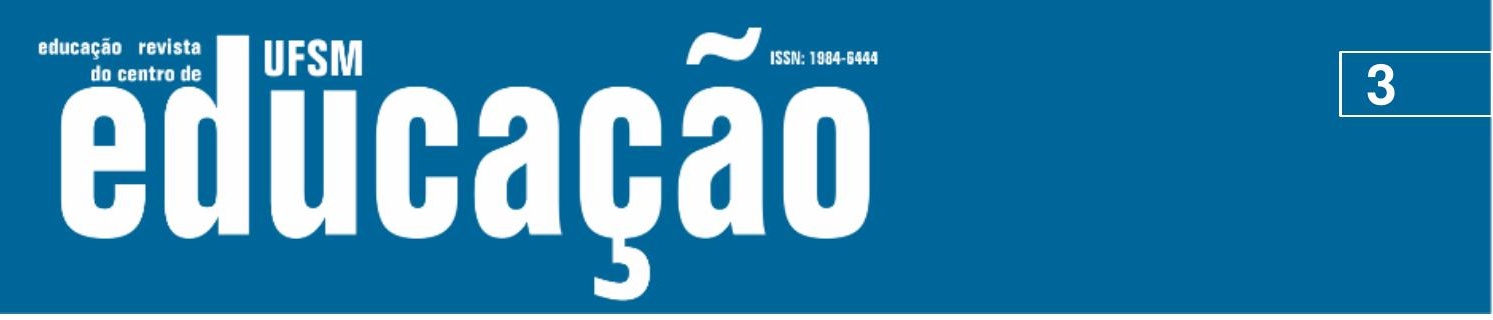

ISSN: 1984-6444 | http://dx.doi.org/10.5902/1984644445787

\section{Introdução}

Considerando a Escola como espaço de aquisição e construção de conhecimentos, de libertação de ideias, de aceitação das diferenças, de valorização da igualdade, deve-se ver a inclusão educacional como algo indispensável à efetivação de educandos na Sociedade, principalmente e atinente às pessoas com Necessidades Especiais Específicas (NEE). Assim, ao estabelecer propostas que estimulem a permanência dos educandos com deficiências na Rede Pública de Ensino Básico, tem-se que criar mecanismos que estimulem e deem condições igualitárias de aprendizagem, principalmente em regiões deficitárias de assistencialismos, como no Estado do Amapá.

Neste contexto, o Centro de Apoio Pedagógico ao Deficiente Visual (CAP-DV) mantém sua ação em consorciação com a Secretaria de Educação do Amapá, bem como presta assessoria no sentido de oferecer orientações pedagógicas, formação continuada aos educadores e atitudinais para alunos cegos ou com baixa visão, pertencentes às Instituições de Ensino Público, Institutos Federais de Educação e comunidade em geral. Através deste estudo, busca-se afervorar os questionamentos sobre como se dá a inclusão de fato, e como o órgão especializado, em indicativo CAP, com caráter normativo, consultivo e deliberativo, contribui para a efetivação da inclusão dos educandos nas unidades de ensino e na sociedade. Partindo do pressuposto de que o Centro busca desenvolver, disseminar e identificar estratégias no âmbito educacional, que visem a desmarginalização da pessoa com deficiências visuais, além de sanar as carências nas áreas da educação, neste caso, na Disciplina de Química, pretende-se, com o levantamento realizado, asseverar e discutir as necessidades do uso da Grafia Química Braille como instrumento articulador do ensino e promotor da manutenção dos alunos nas unidades educacionais assistidas nos últimos 15 anos pelo CAP no Estado do Amapá.

O Núcleo de Produção Braille (NPB), frente a constatação de baixo aproveitamento disciplinar de Química, tem desenvolvido inovação pedagógica para promover as práticas de ensino e consolidar as habilidades agregadas à área de 


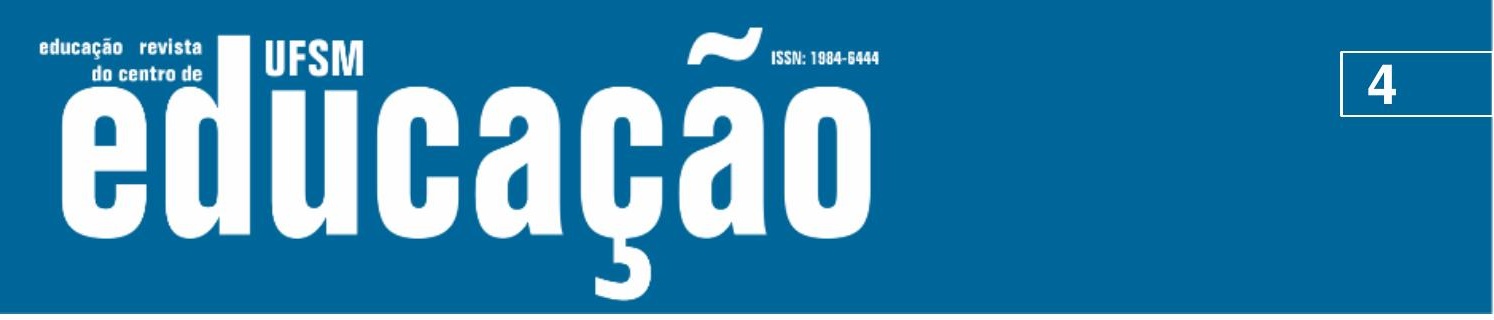

ISSN: 1984-6444 | http://dx.doi.org/10.5902/1984644445787

Química, incrementando as representações e comunicações, de investigação e compreensão e de contextualização sócio-histórica necessária na efetivação do ensino de Química para os Deficientes Visuais (DVs).

Em geral, estudar Química sem uma orientação didática pode ser uma atividade exaustiva e pouco atrativa para os alunos, principalmente para aqueles com NEE. Assim, a complexidade de símbolos específicos da matéria torna-se incipiente quando restritas às abordagens audiodescritivas ou visoespaciais, em que este é anulado quando trata-se dos DVs. Decorrente aos fatos, o educador tem necessidade de buscar recursos facilitadores da aprendizagem e tornar as aulas de Química mais agradáveis de uma forma não visual, porém, devem ser atrativas e dinâmicas para os alunos DVs, a fim de assegurar uma educação igualitária em relação aos demais alunos. No entanto, garantir a efetiva inclusão em espaços escolares requer, dentre outros, o dinamismo dos educadores e, por vezes, apoio de órgãos especializados, além de uma ação conjunta das estratégias e recursos já existentes no meio pedagógico que congruirão para a facilitação e compreensão dos educandos com deficiências visuais, como o uso de materiais didáticos adaptados, por exemplo.

O Centro de Apoio Pedagógico ao Deficiente Visual do Amapá, na última década e meia, tem atendido o Estado e empreendido esforços no sentido de minimizar e, consequentemente, eliminar empecilhos físicos encontrados ao longo da vida acadêmica dos DVs.

Subestruturado nas políticas públicas e iniciativas escolares voltadas ao desenvolvimento das Ciências da Natureza e Matemática, o CAP, atuante na formação Didático-Pedagógica dos professores da Rede Pública de Ensino, com a formação continuada e avaliação escolar dos DVs, detectou as seguintes problemáticas: ausência de materiais didáticos adaptados para o ensino da Química e Ciências em geral, baixo rendimento dos educandos não videntes, quando não atendidos pelo Atendimento Educacional Especializado (AEE), falta de material orientador em relação à prática docente do professor regente das salas inclusivas e o baixo aproveitamento dos DVs na Disciplina de Química ao longo dos últimos 5 anos. 


\section{U usm

ISSN: 1984-6444 | http://dx.doi.org/10.5902/1984644445787

aquilo que chega pela fala dos que a rodeiam (AMIRALIAN, 1997). Logo, o educando cego, em processo escolar, necessita de adaptações adequadas ao nível de conhecimento tátil-cinestésico, auditivo, olfativo e gustativo - em especial aos materiais ligados ao ensino de Química, devido a sua complexidade representacional, necessitando de definições tateáveis e braille descritivas (NUNES, 2010).

A adequação de materiais tem o objetivo de garantir o acesso às mesmas informações que as outras crianças têm, para que a criança cega não esteja em desvantagem em relação aos seus pares. A educação do deficiente visual é marcada pela relação intrínseca com o atendimento especializado, capaz de suprir as necessidades especiais advindas da falta de visão e assegurar o ensino formal deste aluno. Esse atendimento especializado deve ser garantido pela chamada educação especial.

\section{Metodologia}

Em caminhadas que ensejam grandes descobertas, necessita-se de referenciais teórico-metodológicos que possam orientar o desenvolvimento desta pesquisa. Observa-se na figura 1 o panorama geral das etapas da pesquisa. 


\section{工 Tism

ISSN: 1984-6444 | http://dx.doi.org/10.5902/1984644445787

Figura 1 - Fluxograma metodológico das etapas realizadas na Pesquisa

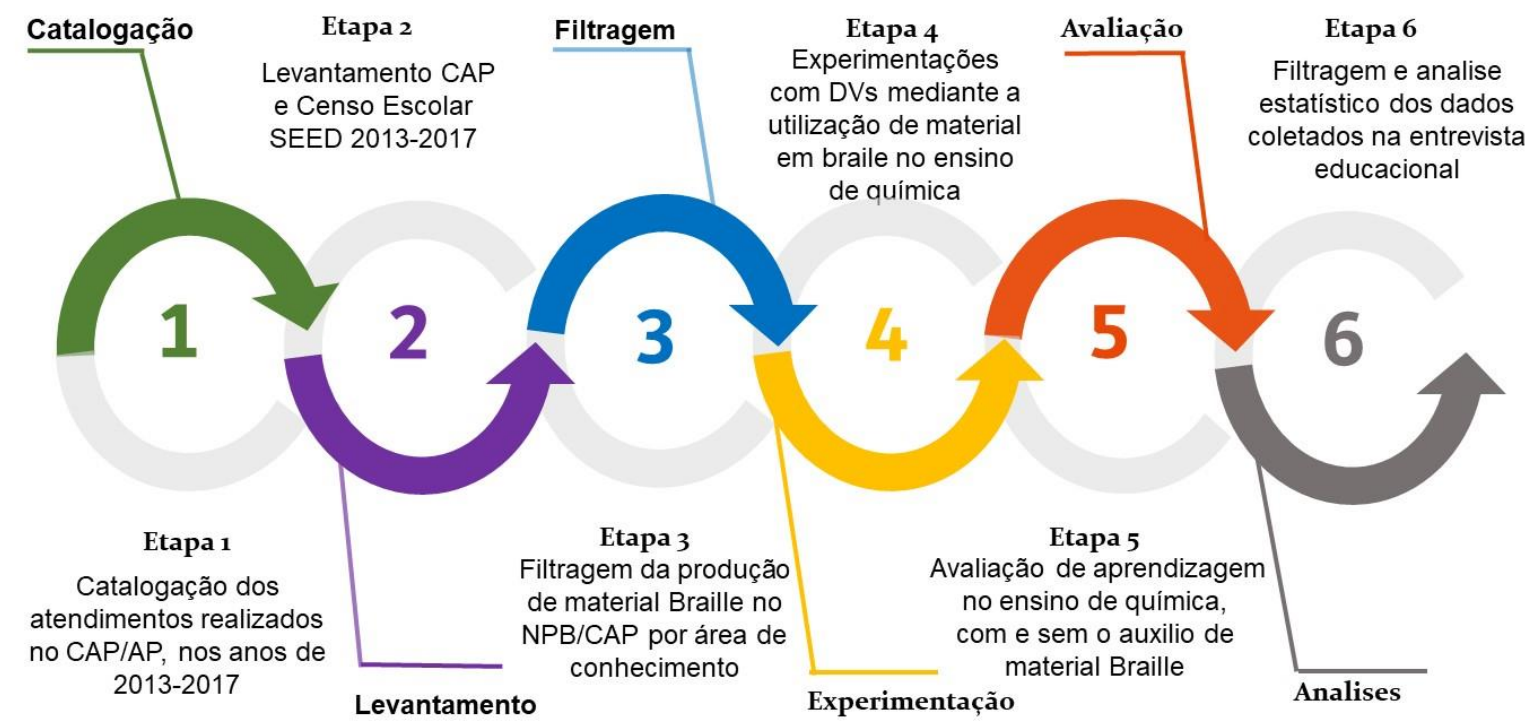

Fonte: Elaborada pelo autor.

No primeiro momento, há o aprofundamento da abordagem qualitativa, contemplando aspectos teóricos da investigação que contribuam para o campo da educação especial, delimitando-se aos indivíduos com deficiência visual, atendidos pelo Centro de Apoio Pedagógico ao Deficiente Visual do Amapá.

Quanto ao método de recolha e análise de dados, a caracterização desta pesquisa está fundamentada na análise documental do CAP e levantamento dos dados obtidos pelo Censo Escolar da Secretaria do Estado de Educação do Amapá (SEED/AP), uma vez que se lançou mão de informações e de atendimentos realizados pelo Centro Pedagógico ao DV, em que foram analisados os registros escritos e abordados como fonte de informação da pesquisa.

Esse tipo de abordagem qualitativa, cujos documentos são objetos únicos de estudo, é extremamente rica em informações; e quando tais documentos são desnudos, mostram o perfil de determinada população (BELL, 2005). A análise destes implica em várias averiguações, ações e transformações dos dados recolhidos com o objetivo de atribuir-lhes significados relevantes às questões investigadas (FLORES, 1994). 


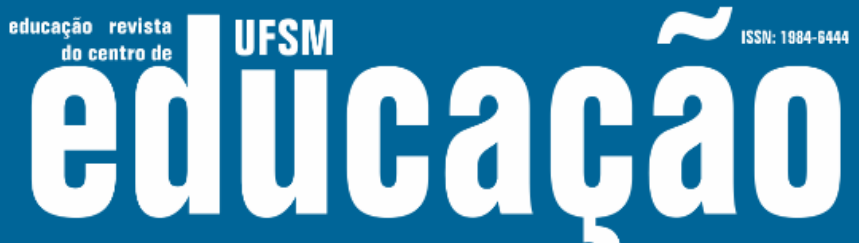

ISSN: 1984-6444 | http://dx.doi.org/10.5902/1984644445787

condições ambientais, físicas, psicológicas e econômicas, que ocorrem em determinada sociedade, ou de fenômenos de diversas naturezas, pertencentes a outras ciências, como física, química, biologia, entre outras.

A obtenção de dados da pesquisa foi executada em 3 (três) atos: no primeiro, houve a aplicação de uma aula tradicional sobre o conteúdo Tabela Periódica e, em seguida, executou-se um questionário estruturado, fechado, composto por 4 (quatro) questões referentes ao assunto. No segundo instante, teve-se a intervenção sobre o assunto com auxílio de material tátil e, posteriormente, o questionário foi refeito. Para testar a hipótese, foi realizado o levantamento dos questionários (antes e depois da intervenção) no programa Graph Prism Instat $3 \AA$ e Statistica 8.0. A análise de dados da pesquisa objetiva a comparação dos resultados e a constatação ou não da melhoria do ensino-aprendizagem a partir da abordagem com material tátil.

\section{Antes da intervenção (Al)}

No processo de ensino-aprendizagem existem, pelo menos, dois sujeitos, o aluno e o professor, e há uma relação entre eles (SÁ; MOURA, 2008; ZANI; NOGUEIRA, 2006). Neste sentido, buscou-se, através de uma aula expositiva, dialogar sobre os conceitos prévios dos participantes da pesquisa sobre o conteúdo Tabela Periódica, fundamentando-a com subitens do conteúdo, tais como: breve histórico da origem da Tabela Periódica, elementos químicos naturais e artificiais, número atômico $(Z)$, número de massa $(A)$, grupos e/ou famílias e períodos. $E$, a fim de coletar dados, executou-se um questionário fechado.

\section{Intervenção (I)}

As aulas de intervenção foram realizadas no período de outubro a dezembro de 2018. Os participantes receberam as aulas individualmente por docentes licenciados em Química, juntamente com um docente especialista na área de Deficiência Visual. Geralmente, o ensino de Química tem sido abordado de maneira bastante teórica e com pouca ou nenhuma conexão com a vida do aluno (BRASIL, 1999). 


\section{Aillbapẫ \\ 3}

ISSN: 1984-6444 | http://dx.doi.org/10.5902/1984644445787

Neste sentido, iniciaram-se as aulas de maneira expositiva, dialogando com a utilização dos materiais táteis, que são: uma tabela periódica adaptada em braille, composta de elementos químicos, número atômico $(Z)$, número de massa $(A)$, grupos e/ou famílias e períodos.

A aula dialogada visa tornar o indivíduo um ser ativo neste processo de ensino-aprendizagem, possibilitando a criação de um ambiente mais favorável e facilitador de aquisição de conhecimentos por meio de troca (MELO; MELO, 2005). A partir disso, nesta pesquisa, o docente realizou a intervenção com exposição do conteúdo, mediando as abordagens deste com a inserção do trabalho tátil através da tabela periódica e, conforme os subitens do conteúdo, o docente demonstrava onde e como encontrar tais informações contidas na tabela. Logo, o que antes ficava apenas registrado na memória através da oratória, passou a ser palpável e registrado.

\section{Depois da intervenção (DI)}

Para fins de apresentação de resultados, optou-se pela aplicação de um questionário após a intervenção, que visa compreender se houve o desenvolvimento da proposta de utilização dos materiais táteis junto às aulas expositivas.

\section{Resultados e discussões}

Esta pesquisa realizou um levantamento sócioestatístico dos últimos cinco anos, 2013 a 2017, quanto ao número de atendimentos do Núcleo de Produção Braille (NPB) do CAP - Amapá, e também dos dados obtidos através do Censo Escolar da Secretaria do Estado de Educação do Amapá (SEED), considerando a quantidade de estudantes com cegueira matriculados nas instituições de ensino de Macapá/AP, como mostra o gráfico 1. 


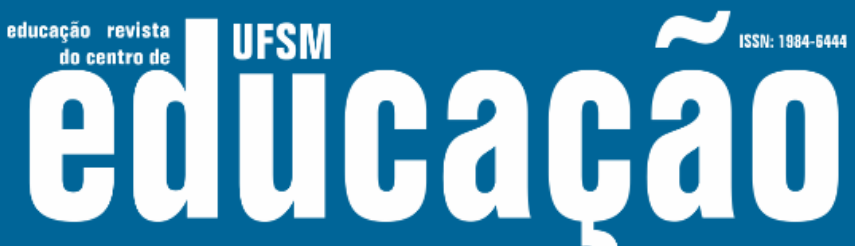

ISSN: 1984-6444 | http://dx.doi.org/10.5902/1984644445787

Gráfico 1 - Alunos Cegos Matriculados segundo Censo Escolar x Alunos Cegos Atendidos pelo CAP/AP

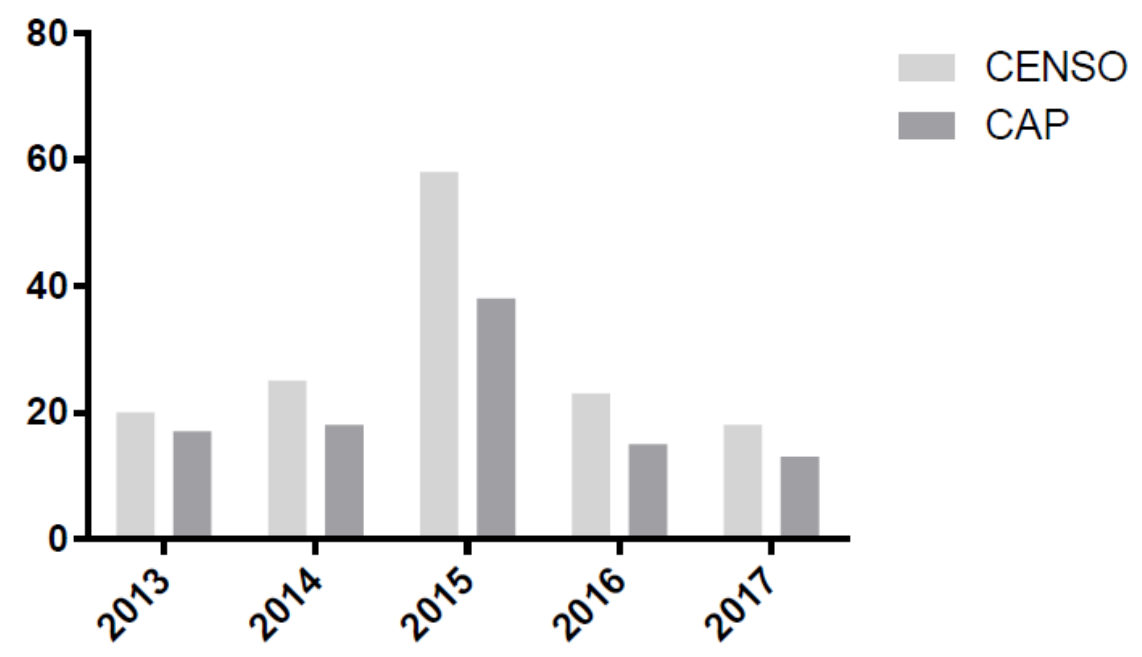

Fonte: Elaborado pelo autor.

Em análise cronológica, o CAP detém $70 \%$ dos atendimentos voltados à população de alunos cegos, regularmente matriculados nas unidades educacionais do Estado, não desacerbando o índice de solicitações das escolas. De um modo geral, isso demonstra que as mesmas não estão totalmente preparadas para atenderem os educandos com deficiências visuais, logo atribuindo as necessidades de suplementação em braille para o Centro Especializado.

Este fato coincide com o cenário nacional, como observado nos estudos realizados por Oliveira e Leite (2011), em que, ao traçar o perfil das escolas brasileiras, detectou-se que em muitas unidades educacionais, apesar de possuírem professores que realizam atendimento do $A E E$, este serviço não é eficiente, devido à falta de formação voltada à área de Educação Especial; e quando especializados, não dominam, em plenitude, as normas técnicas para adaptação e transcrição braille, fazendo-se necessária a atuação de órgãos especializados, no caso o CAP, nosso objeto de estudo.

Assim, os atendimentos ofertados pelo CAP são extremamente importantes para o aluno com deficiência visual, pois ele precisa do material didático adaptado em relevo e braille para ter um aproveitamento satisfatório em sala de aula, de modo 


\section{F HWM

ISSN: 1984-6444 | http://dx.doi.org/10.5902/1984644445787

que possibilite as mesmas condições de aprendizagem proporcionada aos demais educandos. Ou seja, a escola deve estar preparada para receber todos os indivíduos, independente das suas especificidades (BRASIL, 2003).

Outro momento em que o CAP destaca-se como referência é nas adaptações e transcrições do livro didático para o código braille - "principalmente os ligados ao ensino de Química" destinados às salas de AEE do Estado. Estas solicitações são impulsionadas devido as unidades educacionais serem carentes de modernização dos espaços especializados, pois, em geral, não possuem impressoras, materiais didáticos adaptados ou sistema de voz para leitura de tela. Em outra perspectiva, o crescimento das solicitações, segundo Santos et al. (2014), evidencia o que ocorreu nos últimos anos: os livros didáticos estão sobrecarregados com muita linguagem visual (desenhos, tirinhas, fotos, entre outros), tornando-os bastante interessantes para os alunos que enxergam, mas que criam dificuldades para os deficientes visuais, daí a migração dos livros das bibliotecas escolares para o NPB.

Tomando-se por base esses fatos, realizou-se um levantamento dos materiais solicitados para impressão em braille ao NPB-CAP. Assim, a catalogação da pesquisa exprime as três grandes áreas de conhecimento, conforme apresentamos no gráfico abaixo:

Gráfico 2 - Material solicitado ao CAP divididos nas Áreas de Conhecimento

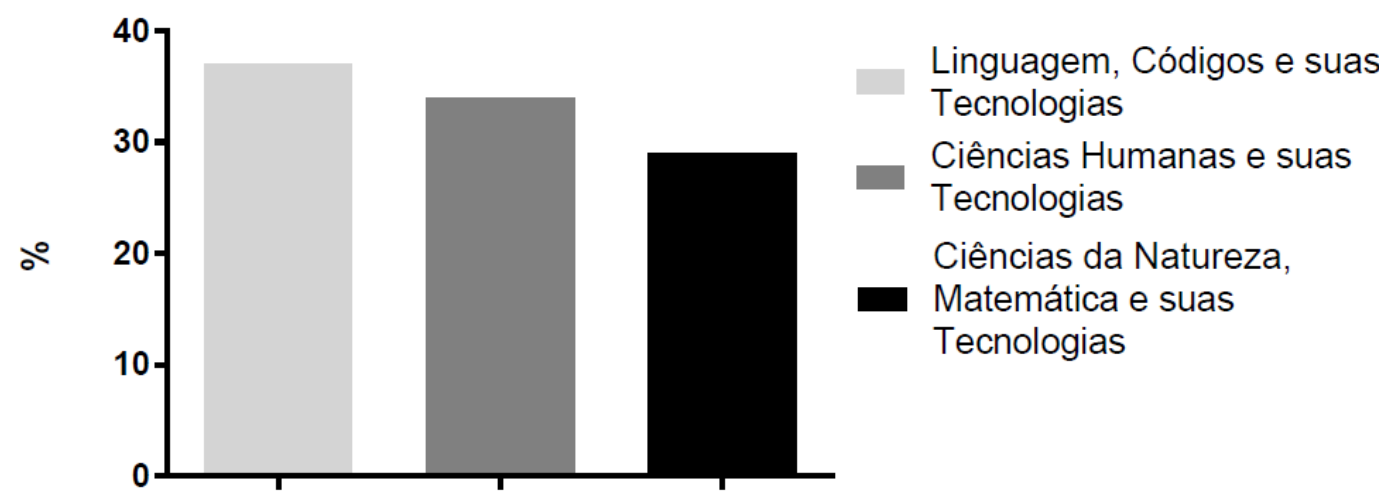

Áreas de Conhecimento

Fonte: Elaborado pelo autor. 


\section{Aillbapẫ}

ISSN: 1984-6444 | http://dx.doi.org/10.5902/1984644445787

Os dados apresentados indicam que $37 \%$ do material adaptado são da área de Linguagem, Códigos e suas Tecnologias, em sequência, tem-se com 34\% a área de Ciências Humanas e suas Tecnologias, seguidos da área de Ciências da Natureza, Matemática e suas Tecnologias, com 29\%.

Ainda que a área de Ciências da Natureza apresente menos solicitações, sabe-se que as disciplinas de exatas necessitam de mais adaptações devido ao grande uso de diversos gráficos, tabelas, formas e esquemas, e os ledores de telas não apresentam total eficiência, pois os programas que leem textos no computador não conseguem descrever determinados conteúdos, como os abordados na química orgânica, inorgânica e físico-química (ALBANO; NOGUEIRA, 2010).

Essas especificidades da área de exatas criam obstáculos na aprendizagem dos alunos DVs quando ausentes os materiais adaptados em relevo, e se a pessoa cega no processo de aprendizagem tem obstrução nas informações e conhecimentos referente à disciplina, sua interação e participação nas aulas tornamse prejudicadas e inservíveis (VIGINHESKI et al., 2014).

Considerando enfatizar a área de Ciências da Natureza, Matemática e suas Tecnologias, o gráfico 3 mostra o quantitativo em relação aos materiais solicitados para impressão em braille ao NPB do CAP, esmiuçando por disciplina.

Gráfico 3 - Material solicitado ao CAP somente da área de Ciências da Natureza, Matemática e suas Tecnologias

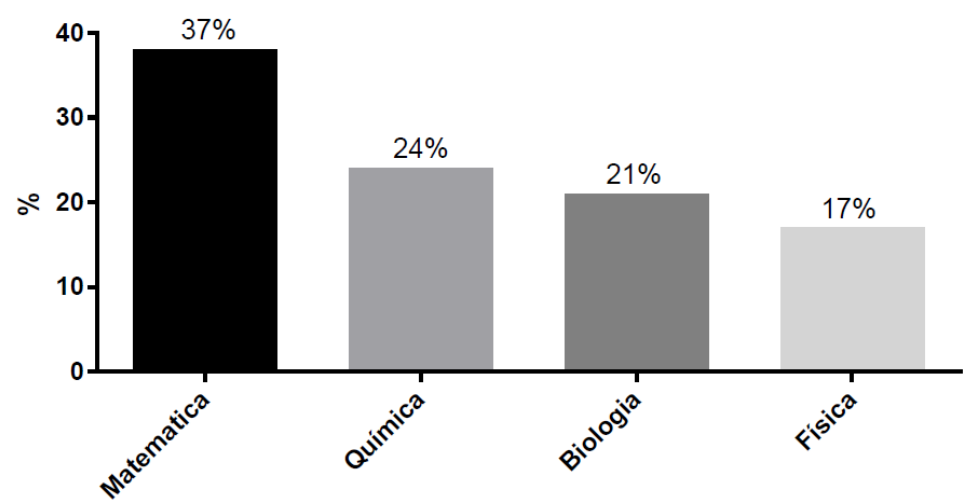

Fonte: Elaborado pelo autor. 


\section{Aithoapẫ

ISSN: 1984-6444 | http://dx.doi.org/10.5902/1984644445787

$\mathrm{Na}$ análise do gráfico 3, percebe-se que a disciplina de Química destaca-se com percentual de $24 \%$ em correlação às disciplinas da área de ciências exatas, cujos materiais foram solicitados e atendidos no NPB; a disciplina de Matemática representa $37 \%$ dos materiais transcritos em braille. No entanto, mesmo com essa porcentagem, estima-se que é baixa a procura de tais materiais para a disciplina de Química, pois ela é, muitas vezes, considerada abstrata pelos DVs.

Subjetividade essa, questionada por Beckers, Pereira e Trogello (2014), ao corroborarem que aulas contínuas, expositivas e extremamente visuais desfavorecem a ideia de inserir os DVs na comunidade escolar, pois, em aproveitamento efetivo, as disciplinas trabalhadas nas aulas precisam ser adaptadas às especificidades presentes no âmbito educacional, $e$ os instrumentos proporcionadores são os materiais adaptados em braille.

Em contrapartida, a compreensão dos alunos não videntes, ao serem estimulados apenas com a explicação verbal do professor, torna-se mais difícil, carecendo da ampliação de formas explicativas do conteúdo, como a utilização de elementos químicos entrelaçados em conceitos, discursos e materiais adaptados, essenciais na construção e assimilação de novos conhecimentos ao indivíduo cego (FERNANDES; HUSSEIN, DOMINGUES, 2017).

Perseverando a necessidade de subsidiar os DVs com materiais em braille durante o ciclo educacional básico, faz-se insociável o ingresso paulatinamente dos educandos não videntes em classes comuns, descartando a possibilidade de mera inserção (ROCHA; MIRANDA, 2009). Com a insociabilidade do material didático em braille e rendimento educacional, o CAP monitorou o aproveitamento disciplinar referente à disciplina de Química, exposto no gráfico 4, em termos de etapas do ensino médio e grupos de educação DVs assistidos com e sem suplementação em braille. 


\section{$\sim 7$

ISSN: 1984-6444 | http://dx.doi.org/10.5902/1984644445787

Gráfico 4 - Nivelamento das Médias da Disciplina de Química dos Grupos sem/com Complementação do CAP na vida educacional

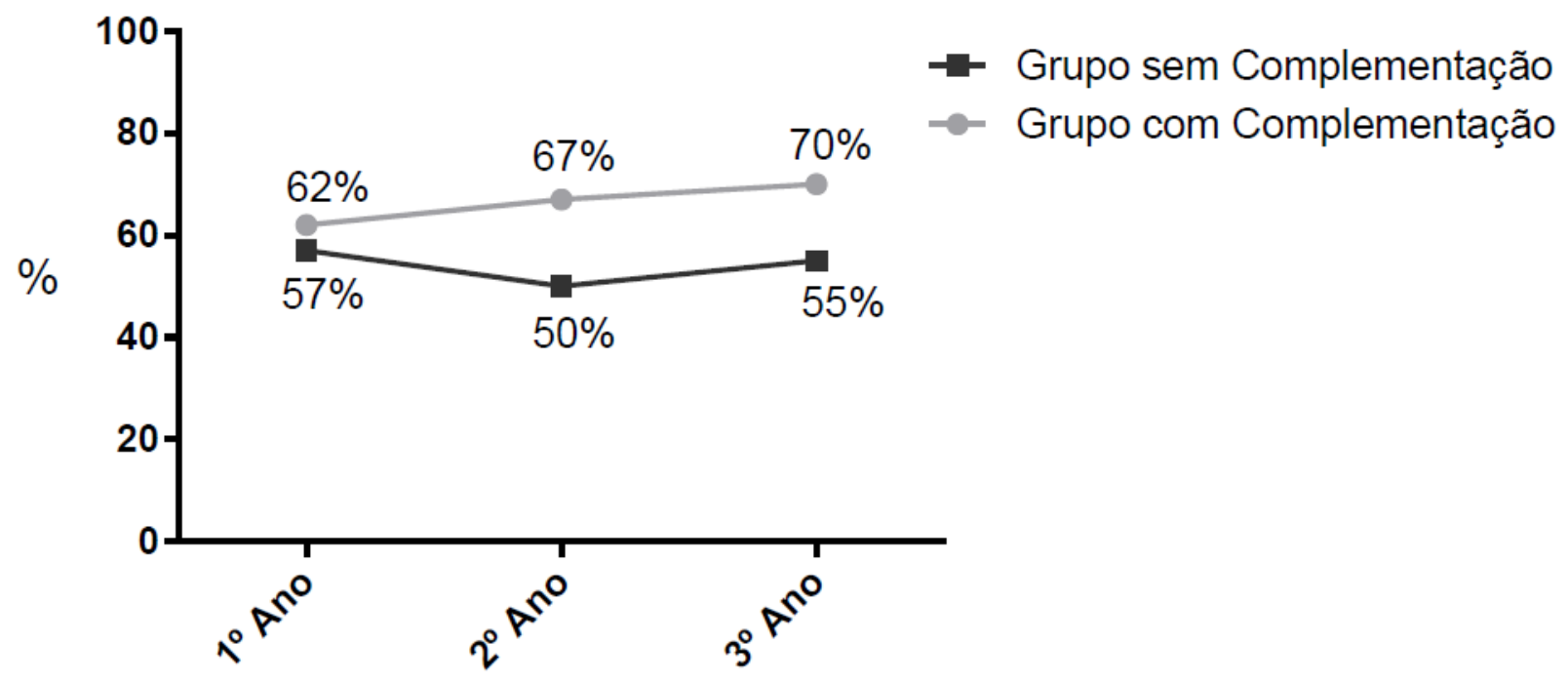

Fonte: Elaborado pelo autor.

Validade essa que Smith e Strick (2001), ao afirmarem que as dificuldades de aprendizagem podem resultar de problemas de inclusão, escolas superlotadas, mal estruturadas, falta de materiais didáticos específicos a cada necessidade, professores mal preparados e desmotivados e marginalização dos educandos com necessidades especiais específicas, "como DVs", afetando diretamente o rendimento escolar, principalmente nas disciplinas de exatas.

Assim, observa-se a concretização do estudo realizado por Smith e Strick (2001) ao verificarmos as estatísticas de rendimento do grupo sem complementação de material didático em braille, com média anual de $57 \%, 50 \%$ e $55 \%$ para o $1^{\circ}$, 2ํㅡ e $3^{\circ}$ anos, respectivamente. Já para o grupo suplementado com transcrição em braille, verifica-se ascensão do aproveitamento escolar para os três níveis do ensino básico, com $62 \%, 67 \%$ e $70 \%$, respectivamente aos níveis de escolaridade.

A concretização da indubitabilidade do experimento e efetividade da inclusão dos DVs no Estado do Amapá pode ser traçada quando subjetivada a medida de aproveitamento do grupo com complementação, resultando em 65\%. Estes dados foram correlacionados aos experimentos similares realizados por Correia et al. (2010) no Estado do Mato Grosso do Sul, onde a média de grupos trabalhados 


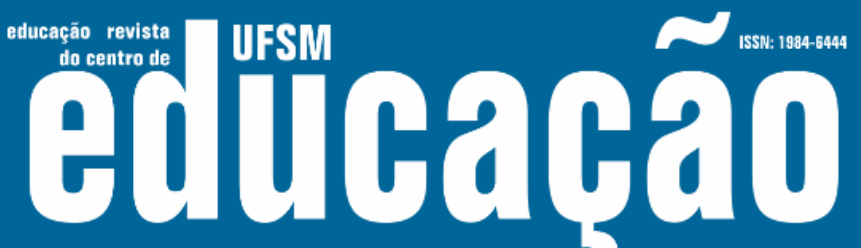

ISSN: 1984-6444 | http://dx.doi.org/10.5902/1984644445787

experimentalmente formam $68 \%$ de aproveitamento na disciplina de Química. Vale ressaltar que são videntes utilizando material suplementar com adaptações voltadas para a disciplina de Química, o que não apresenta disparidade excessiva em relação aos DVs amapaenses resultados por material braille.

$\mathrm{Na}$ tentativa de ratificação em evidenciar as dificuldades dos alunos cegos em relação ao ensino de Química sem recursos didáticos, a proposta de intervenção, realizada nos meses de outubro a dezembro do ano de 2017, investigou o ensinoaprendizagem de um grupo de participantes deficientes visuais em relação ao ensino de Química, intercalando as atividades com e sem o auxílio de materiais táteis. Vale ressaltar que todos os indivíduos do grupo de pesquisa receberam o AEE em diferentes etapas de sua formação educacional, porém uma parcela foi atendida pelo Centro de Apoio Pedagógico do Estado do Amapá, órgão que atende as demandas de materiais devidamente adaptados conforme as necessidades individuais. Comparando com as dificuldades apresentadas (Al), todos os participantes da pesquisa, $A, B, C, D, E$ e $F$, demonstraram aumento no rendimento (DI), como mostra o Gráfico 5.

Gráfico 5 - Rendimento dos Participantes da Pesquisa Al e DI

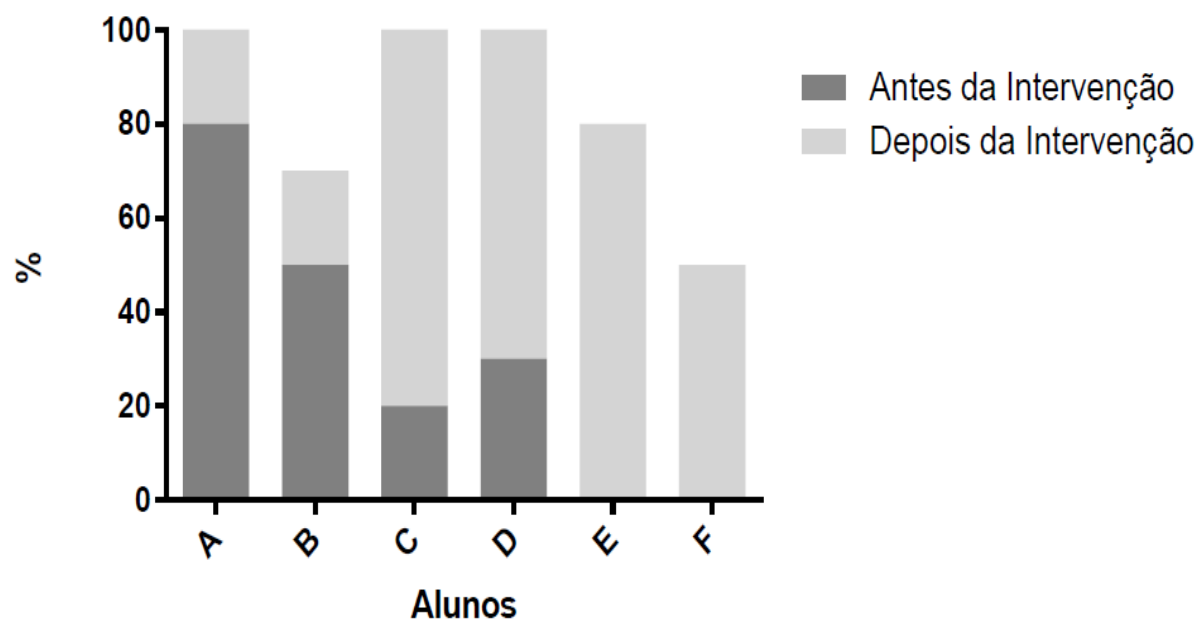

Fonte: Elaborado pelo autor. 


\section{Fism

ISSN: 1984-6444 | http://dx.doi.org/10.5902/1984644445787

Após observação do Gráfico 5, percebe-se que houve um progresso DI em relação à utilização dos materiais táteis como complementação às aulas de Química propostas na pesquisa.

Os participantes Al apresentaram um percentual de $30 \%$ e, posterior à intervenção, atingiram $80 \%$ no rendimento. Nota-se o aumento de $50 \%$ de melhoramento dos participantes com a utilização dos materiais de apoio nas aulas de Química.

Para os alunos deficientes visuais, os materiais didáticos são essenciais, uma vez que a falta visual do ambiente físico dificulta a construção de conceitos, além de ficarem presos ao verbalismo. Por isso, há a necessidade de adaptação ou confecção de materiais para suprir as informações que eles não conseguem perceber (CERQUEIRA; FERREIRA, 1996). Ratificado assim, dentro dos resultados obtidos na primeira fase da pesquisa experimental.

Para melhor análise de rendimento, optou-se por organizar os participantes em grupos segundo seu grau de escolaridade. Assim, temos: participantes A e B (alunos do $1^{\circ}$ ano do E. M.), participantes C e D (formados no Ensino Médio) e participantes $E$ e $F$ (acadêmicos do Ensino Superior). Em seguida, para esta análise de dados, iniciou-se a quantificação de acertos do Grupo AB (Gráfico 6).

\section{Gráfico 6 - Acertos Al e DI do Grupo AB}

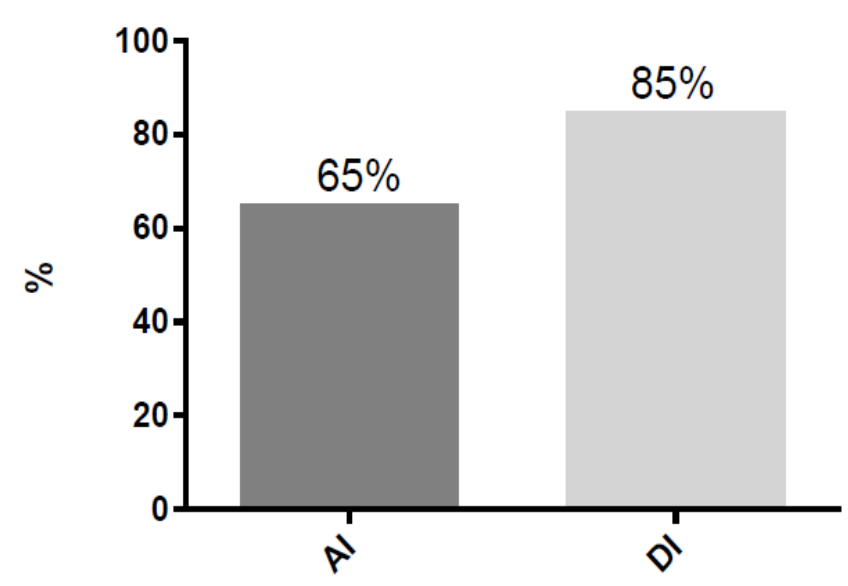

Fonte: Elaborado pelo autor. 


\section{N uss

ISSN: 1984-6444 | http://dx.doi.org/10.5902/1984644445787

Ao examinar os participantes do primeiro grupo, $A B$, ambos na mesma série do Ensino Médio, temos o participante A com 80\% Al e 100\% DI. Este participante recebe atendimento do CAP desde o início de sua vida estudantil, foi alfabetizado em braile, recebeu continuamente materiais adaptados de acordo com as demandas solicitadas, mostrando-se habilidoso no manuseio de materiais táteis, bem como na assimilação de contextos a partir dos mesmos.

O participante B apresentou 50\% Al e 70\% DI de rendimento. Este também foi alfabetizado em braille e passou a receber atendimento parcial pelo CAP no presente ano. Porém, este caso se limita a atendimento parcial devido o docente do AEE executar a maior parte das atividades do participante. Fato este refletido no baixo rendimento do aluno que, por sua vez, não faz uso do material adaptado, recebendo, em sua maioria, aulas por oratória.

Segundo Nunes e Lomônaco (2010), quando não há esse atendimento especializado, o aluno cego somente utiliza a fala do professor como recurso didático, mas quando há fórmulas, mapas, esquemas, desenhos, entre outros recursos, a aprendizagem desse aluno fica prejudicada, além de poder causar baixa autoestima por se sentir excluído da aula. Tal compreensão revela o desnivelamento de aprendizado quando comparados os resultados dos indivíduos $A$ e $B$ que, juntos, apresentam um rendimento de $65 \% \mathrm{Al}$ para $85 \% \mathrm{DI}$, demonstrando o melhoramento da aprendizagem oriunda de aulas teóricas com auxílio de materiais didáticos adaptados.

Durante a pesquisa, pode-se observar que o material tátil, utilizado continuamente, tornar-se-ia cada vez mais eficaz quando conciliado ao ensino de Química para os DVs, porém analisaremos os demais grupos para melhor constatar esta teoria (Gráfico 7). 


\section{تulloapẫ}

ISSN: 1984-6444 | http://dx.doi.org/10.5902/1984644445787

Gráfico 7 - Acertos Al e DI do Grupo CD

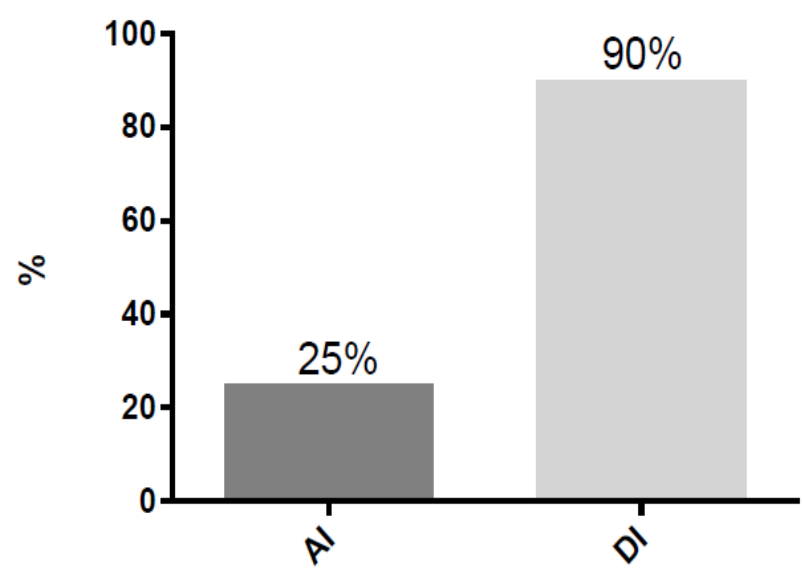

Fonte: Elaborado pelo autor.

Os participantes $C$ e $D$ constituem o segundo grupo, que é formado por quem concluiu o Ensino Médio (E.M.). Quando quantificados os resultados, o indivíduo C apresenta $20 \%$ Al e $100 \%$ DI. Este finalizou o E.M. no ano precedente, foi usuário do CAP e atendido (alfabetizado) pelo AEE durante sua formação escolar; realizou, ainda, após o término do E.M., cursos de braille básico e braille avançado para melhor domínio, devido apresentar dificuldades no ensino de Matemática e Química. E o indivíduo D obteve 30\% Al e 80\% DI de aproveitamento. Concluiu o E.M. no ano de 2003, foi alfabetizado pelo AEE da instituição de ensino e realizava o atendimento pelo CAP, o que justifica sua fluidez na leitura braille, bem como a facilidade no manuseio de materiais adaptados, os quais favorecem o seu ensinoaprendizagem.

Ambos, C e D, obtiveram, significativamente, um melhoramento de $25 \% \mathrm{Al}$ para $90 \%$ DI quando induzidos a complementarem seu material de estudo com materiais táteis oriundos desta pesquisa. Ainda que os participantes mostrem não ter afinidade com a disciplina de Química, o uso do material tátil instigou-os a participarem com maior entusiasmo da aula ministrada na intervenção, aumentando a interação teórica e prática.

Quando se utiliza materiais concretos como auxílio nas aulas teóricas, o benefício é para ambos, pois tanto instiga o docente a adquirir um contato com 


\section{Aillbapẫ}

ISSN: 1984-6444 | http://dx.doi.org/10.5902/1984644445787

inovações didáticas e metodológicas (CONSTABLE; LONG, 1991), quanto estimula o aluno a pesquisar e a procurar novos conhecimentos (FRISON, 2002), além de proporcionar, a este, a construção de uma cultura investigativa, preparando-o para o mundo como sujeito ativo, capaz de solucionar possíveis ações práticas na própria sociedade (ALENCAR, 2002).

Quando avaliados os participantes que concluíram o ensino médio, o Gráfico 8 trata de apresentar os dados Al e DI obtidos dos participante pertencentes a uma Instituição de Ensino Superior, o grupo EF, ou seja, docentes em formação:

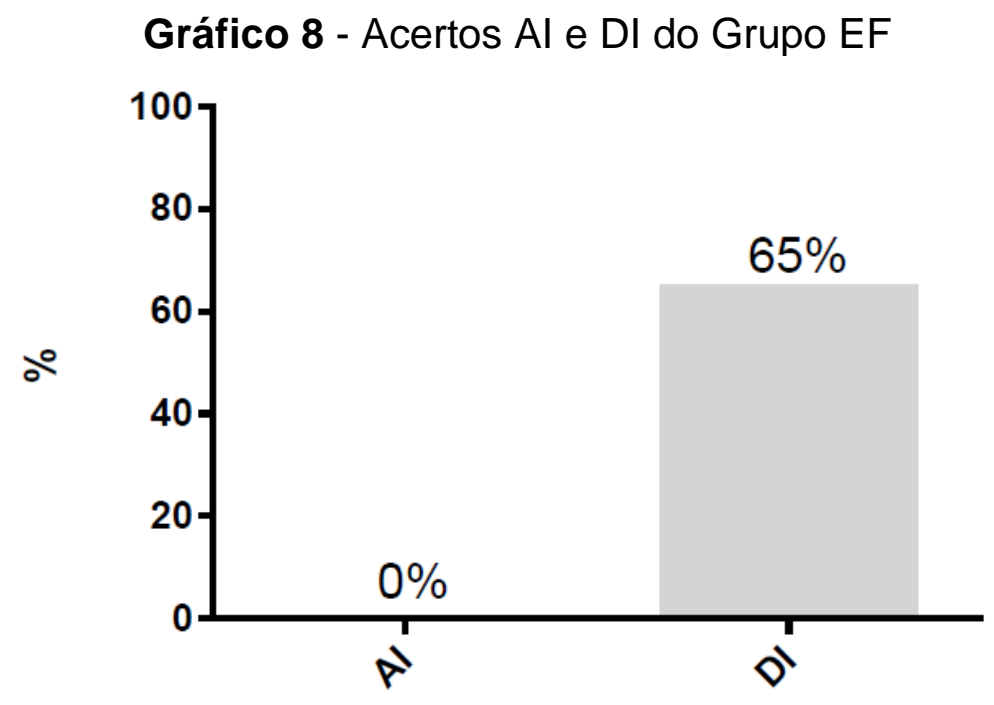

Fonte: Elaborado pelo autor.

O terceiro grupo, EF, é formado por acadêmicos do Ensino Superior, em que o indivíduo E apresenta os seguintes resultados, $0 \%$ Al e $80 \%$ DI. Este foi alfabetizado em braille, atendido pelo AEE durante o ensino médio, matriculado no 6- semestre da Instituição de Ensino Superior (IES) e, atualmente, recebe atendimento da própria IES. Assim também acontece com o participante $F$, que apresentou o percentual de 0\% Al para 50\% DI. Ele é cursista do $8^{\circ}$ semestre da IES e alfabetizado em braille.

Os dois participantes, E e F, são acadêmicos de Ciências Humanas, Pedagogia e Letras, respectivamente. Os resultados Al deste grupo buscaram uma melhor compreensão devido ao baixo rendimento, $0 \%$, pois tais indivíduos não 


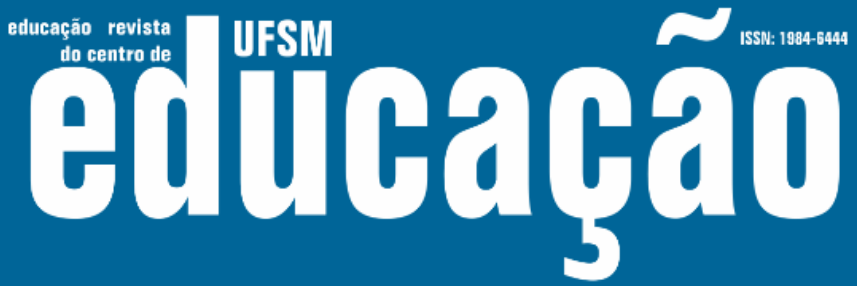

ISSN: 1984-6444 | http://dx.doi.org/10.5902/1984644445787

recebiam durante seu ensino básico materiais adaptados pelo CAP, e o próprio AEE das escolas não possuía docentes devidamente capacitados para as necessidades dos alunos.

Monte Alegre (2003) constatou a falta de apoio especializado no ensino básico, tanto pela ausência de materiais e recursos para 0 atendimento a cegos, quanto por docentes da classe comum não capacitados ou, simplesmente, pela falta de qualificação dos profissionais do AEE de acordo com as necessidades especiais dos alunos, embora a Declaração de Salamanca (BRASIL, 2003), documento que trata dos princípios, da política e da prática da educação para alunos com necessidades especiais em qualquer grau de escolaridade, oriente que as escolas precisam se ajustar às necessidades de todos os alunos.

Segundo Santos e Paulino (2006), o professor necessita estar preparado e assessorado na construção do saber. No entanto, ocorre que os conteúdos de Química, quando abstratos e/ou ensinados de maneira superficial e confusa, geram desmotivação no seu estudo (CARDOSO; COLINVAUX, 2000). Isso leva os professores de Química a sentirem dificuldades de lecionar para alunos com DVs, uma vez que a disciplina apresenta muitos símbolos, reações e cálculos. Portanto, torna-se dificultoso para o docente a transcrição em braille e custoso para o aluno compreender, degradando, bastante, a aprendizagem por parte dos alunos cegos inseridos na educação regular.

Contudo, a análise do rendimento DI do grupo EF, 65\%, destaca que a utilização de materiais adaptados permite ao aluno deficiente visual compreender o conteúdo por meio do tato sensoriamento e, a partir daí, formar a imagem mentalmente e começar a construir seus conceitos e abstrações, interagindo de forma ativa em sala de aula (RAZUCK; OLIVEIRA NETO, 2015).

Ainda neste contexto, sobre tornar as aulas da disciplina de Química mais atrativas por meio da instigação dos participantes, utilizando a tabela periódica como recurso de apoio, verificou-se, no Gráfico 9, os rendimentos dos grupos da pesquisa experimental. 


\section{Tusm

ISSN: 1984-6444 | http://dx.doi.org/10.5902/1984644445787

Gráfico 9 - Análise de Rendimentos dos Grupos Al e DI

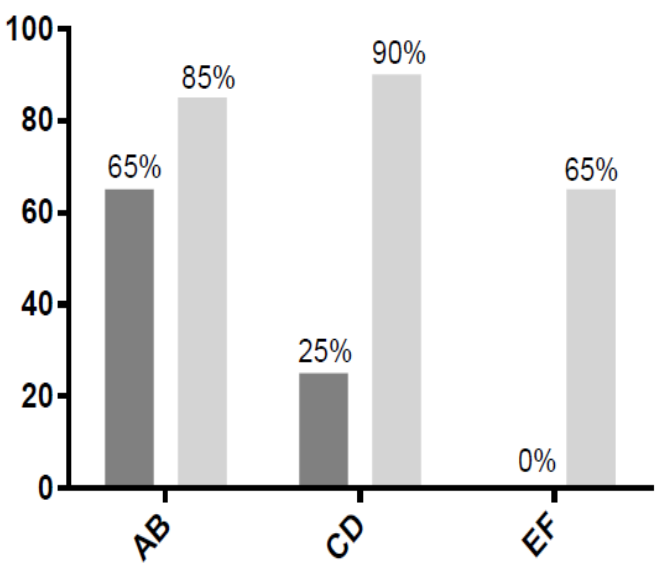

Fonte: Elaborado pelo autor.

Ao compararmos os três grupos da pesquisa, percebe-se que $\mathrm{Al}$, o grupo que expressou a menor média de acertos, $0 \%$, foi o EF, formado por acadêmicos do E.S., seguido pelo grupo CD, com $25 \%$. Destaca-se o grupo EF por não ter tido acompanhamento do CAP, interrompendo, assim, a finalidade precípua do órgão, que é garantir e estimular o acesso de qualidade dos indivíduos cegos ao sistema de ensino (CARBONARI, 2011; MAZZOTA, 1998).

Ao confrontarmos os grupos EF com o $A B$, mostra-se com clareza a diferença de resultados, apresentando o grupo $A B$ com rendimento de $65 \% \mathrm{Al}$, salientando o participante $A$, pois o mesmo recebeu atendimento do CAP desde seu início da vida escolar, o que favoreceu a média de seu grupo. Vale ressaltar que o assunto escolhido, Tabela Periódica, esteja mais próximo da realidade vivenciada em sala de aula dos alunos do $1^{\circ}$ E.M. do que dos acadêmicos que, além de serem da área de Ciências Humanas, não receberam atendimento pelo CAP durante sua formação básica.

Tais resultados refletem na importância do atendimento educacional especializado realizado pelo CAP como sendo fundamental na formação dos educandos, seja qual for o grau de escolaridade. Contrapondo o aproveitamento DI, destacaram-se com maior rendimento os grupos CD e EF, com 65\% de melhoramento, evidenciando uma aprendizagem significativa (MOREIRA; MASINI,1982), uma vez que as aulas da disciplina de Química se tornam mais 


\section{Aillbapẫ \\ 3}

ISSN: 1984-6444 | http://dx.doi.org/10.5902/1984644445787

compreender os conceitos e estruturas químicas específicas quando trabalhadas com alunos DVs.

Em comprobatória às iniciativas do Centro, realizou-se uma série de experimentos com intuito de verificar o aproveitamento da disciplina de Química quando estimulada com auxílio de material didático em braile. Foram pesquisados alunos DVs que receberam atendimento durante todo o ensino básico, parcialmente ou não receberam nenhum atendimento pelo CAP.

A disparidade foi evidenciada nos índices de aproveitamento quando interrelacionados os indivíduos acompanhados durante toda vida escolar, obtendo aproveitamento de até $100 \%$ na disciplina de Química, quando utilizado o material didático adaptado em braille. Já em relação aos indivíduos não amparados pelo CAP em sua vida escolar, obteve-se $0 \%$ de aproveitamento, inicialmente, porém, quando fomentados com materiais produzidos no Centro, evidencia-se um salto no rendimento escolar de até $80 \%$.

Assim, conclui-se que o Centro de Apoio Pedagógico ao Deficiente Visual do Amapá realiza, em plenitude, a inclusão dos DVs, bem como a difusão do Sistema Braille na Região Norte, sendo profícua dentro da disciplina de Química, tornando-se indispensável aos sujeitos cegos no aproveitamento disciplinar e social.

\section{Referências}

ALBANO, Geisa Golin; NOGUEIRA, Ruth Emilia. Serviços públicos e mapas táteis acessíveis via web para usuários deficientes visuais. Revista Democracia Digital e Governo Eletrônico, Florianópolis - SC, v. 2, n. 3, p. 102-118, 2010.

ALENCAR, Eunice Maria Lima Soriano de. O contexto educacional e sua influência na criatividade. Linhas Críticas, Brasília. v. 8, n. 15, p. 165-178, jul./dez. 2002.

AMIRALIAN, Maria Lúcia Toledo Moraes. Compreendendo o cego: Uma visão psicanalítica da cegueira por meio de desenhos-estórias. São Paulo: Casa do Psicólogo/FAPESP, 1997.

BARDIN, Laurence. Análise de conteúdo. São Paulo: Edições 70, 2011. 


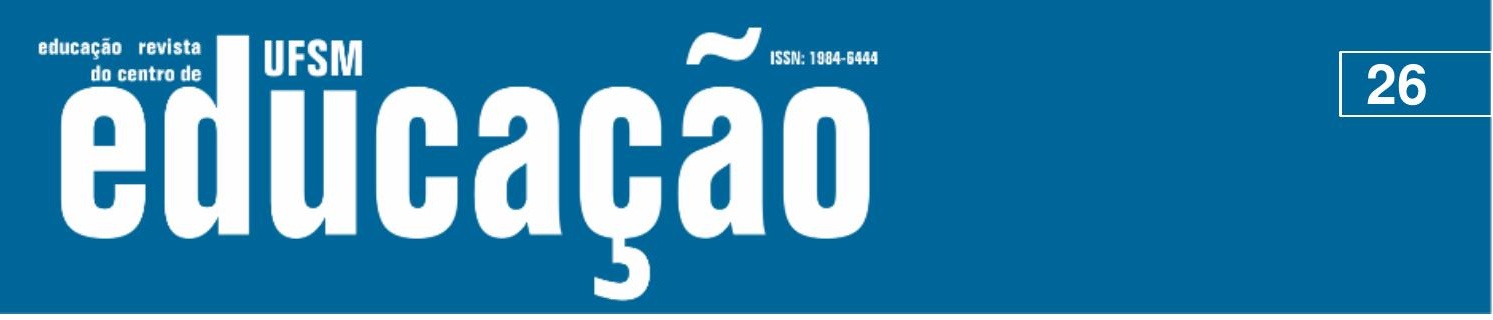

ISSN: 1984-6444 | http://dx.doi.org/10.5902/1984644445787

BARRETO, Mylane Santos. Educação inclusiva-Um estudo de caso na construção do conceito de função polinomial do 1 Grau por Alunos Cegos Utilizando Material Adaptado. 2013. 132 F. Dissertação (Mestre em Matemática)Universidade Estadual do Norte Fluminense Darcy Ribeiro - UENF. Campos Dos Goytacazes-RJ, 2013.

BECKERS, lohanna Elizabeth; PEREIRA, Josefa Lídia Costa; TROGELLO, Anderson Giovani. O processo de ensino-aprendizagem de ciências em turmas com alunos deficientes visuais: percepções dos professores. Revista Educação Especial, Santa Maria, RS, v. 27, n. 48, p. 127-240, 2014.

BELL, Judith. Fazendo seu projeto de pesquisa: um guia para pesquisadores iniciantes em educação e ciências sociais. 4. ed. Buckingham: OUP, 2005

BERTALLI, Jucilene Gordin. Ensino de Geometria Molecular, para alunos com e sem Deficiência Visual, por Meio de Modelo Atômico Alternativo. 2010. 70 F. Dissertação (Mestrado em Ciências) - Universidade Federal de Mato Grosso do Sul, Mato Grosso do Sul, 2010.

BRASIL. Ministério da Educação, Secretaria de Educação. Declaração de Salamanca: recomendações para a construção de uma escola inclusiva. SEESP/MEC, 2003. (Saberes e práticas da inclusão, 3).

BRASIL. Ministério da Educação, Secretaria de Educação. Parâmetros Curriculares Nacionais - Ensino Médio: parte III Ciências da Natureza, Matemática e suas Tecnologias. Brasília: Setec,1999.

CALLEGARI-JACQUES, Sidia Maria. Bioestatísticos princípios e aplicações. São Paulo: ARTMED, 2004.

CAMARGO, Eder Pires; SILVA, Dirceu. Atividade e material didático para o ensino de física à alunos com deficiência visual: queda dos objetos, ENCONTRO NACIONAL DE PESQUISA EM EDUCAÇÃO EM CIÊNCIAS, 6., 2003, Bauru. Anais... Bauru: ABRAPEC, 2003b. p. 1-13.

CAMARGO, Eder Pires; SILVA, Dirceu; VERASZTO, Estéfano Vizconde. O ensino de física, os alunos com deficiência visual e os parâmetros curriculares nacionais. In: SIMPÓSIO EM FILOSOFIA E CIÊNCIA, TRABALHO E CONHECIMENTO: desafios e responsabilidades da ciência. 5., Marilia, SP, 2003. Anais eletrônico... Marilia: UNESP, 2003a. CD-ROM. 


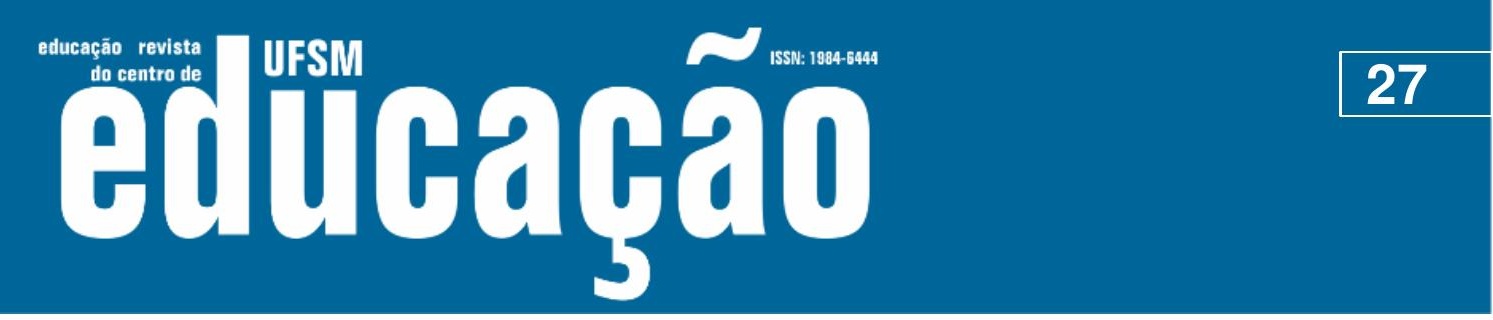

ISSN: 1984-6444 | http://dx.doi.org/10.5902/1984644445787

CARBONARI, Vera Lucia Gomes. As Políticas Públicas da Educação Especial na Perspectiva da Educação Inclusiva da Rede Estadual de Ensino do Estado de Mato Grosso do Sul. In: ENCONTRO DA ASSOCIAÇÃO BRASILEIRA DE

PESQUISADORES EM EDUCAÇÃO ESPECIAL, 7., Londrina, PR, 2011. Anais... Londrina: UEL, 2011. p. 3828-3836.

CARDOSO, Sheila Pressentin; COLINVAUX, Dominique. Explorando a Motivação para Estudar Química. Química Nova, ljuí, v. 23, n.3. p. 401-404, 2000.

CERQUEIRA, Jonir Bechara; FERREIRA, Elise de Melo Borba. Os recursos didáticos na educação especial. Revista Benjamin Constant, Rio de Janeiro, n. 5, p. 3-32, 1996.

CONSTABLE, Hilary; LONG, Andrew. Changing science teaching: lessons from a long-term evaluation of a short in-service course. International Journal of Science Education, London, v.13, n.4, p. 405-419, ago. 1991.

CORREIA, Maria Emanuella Amâncio et al. Investigação Do Fenômeno de Isomeria: Concepções Prévias dos Estudantes do Ensino Médio e Evolução Conceitual. Ensaio, Belo Horizonte, v. 12, n. 02, p. 83-100, 2010.

FACHIN, Odilia. Fundamentos de metodologia. 4. ed. São Paulo: Saraiva, 2005.

FARIAS, Renata Claudia Claudiano. Construção de Modelos Moleculares para o ensino de química utilizando bolinhas de isopor na representação tridimensional das cadeias carbônicas. 201542 F. Monografia (Especialista)Universidade Estadual da Paraíba, 2015. p-12-32, 2015.

FERNANDES, Tatyane Caruso; HUSSEIN, Fabiana R. G. Silva; DOMINGUES, Roberta C. P. Rizzo. Ensino de química para deficientes visuais: a importância da experimentação num enfoque multissensorial. Química Nova na Escola, São Paulo, n. 2, p. 195-203, 2017.

FLORES, Javier Gil. Análisis de dados cualitativos: aplicaciónes a la investigación educativa. Barcelona: PPU, 1994.

FONSECA, João José Saraiva da. Metodologia da pesquisa científica. Fortaleza: UEC, 2002.

FONSECA, Vitor da. Introdução às dificuldades de aprendizagem. Porto Alegre: Artes Médicas, 1995. 


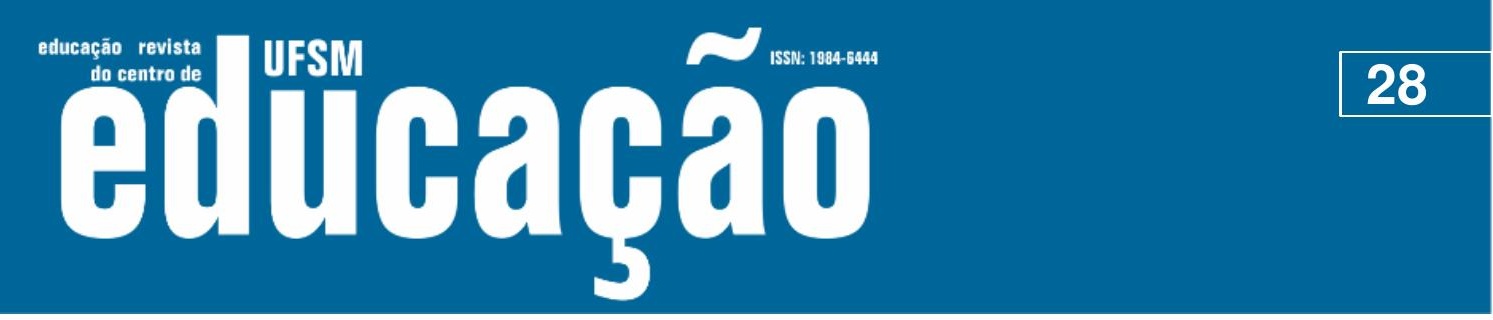

ISSN: 1984-6444 | http://dx.doi.org/10.5902/1984644445787

FRISON, Lourdes Maria Bragagnolo. Pesquisa como superação da aula copiada. In: MORAES, Roque; LIMA, Valderez Marina do Rosário. (Org.). Pesquisa em sala de aula: tendências para a educação em novos tempos. 2. ed. Porto Alegre: EDIPUCRS, 2002. p. 143, 170

GONÇALVES, Renata Barbosa; VIANNA, Carlos Alberto Fonseca Jardim; SANTOS, Sirley Brandão dos. Práticas pedagógicas inclusivas: Materiais didáticos alternativos para o ensino de ciências a alunos com deficiência visual. In: DÍAZ, Felix et al. (org.). Educação inclusiva, deficiência e contexto social: questões contemporâneas. Salvador: EDUFBA, 2009. p. 99-106.

MAZZOTA, Marcos José da Silveira. Inclusão e Integração ou Chaves da Vida Humana. In: CONGRESSO IBERO - AMERICANO DE EDUCAÇÃO ESPECIAL. Diversidade na Educação: Desafio para o Novo Milênio. 3., Foz do Iguaçu, 1998. Anais... Brasília: SEESP/MEC, 1998. p.48-53.

MELO, Elda Silva do Nascimento; MELO, João Ricardo Freire de Softwares de simulação no ensino de química: uma representação social na prática docente. ETD - Educação Temática Digital, Campinas, v. 7, n. 1, 51-63, 2005.

MONTE ALEGRE, Paulo Augusto Colaco. A cegueira e a visão do pensamento. 2003. 303 F. Tese (Doutor em Psicologia)-Instituto de Psicologia, Universidade de São Paulo, São Paulo, 2003.

MOREIRA, Marco Antonio; MASINI, Elcie F. Salzano. Aprendizagem significativa: a teoria de David Ausubel. São Paulo, Editora Moraes, 1982.

NUNES, Albino Oliveira. Abordando as Relações CTSA no Ensino da Química a partir das crenças e atitudes de licenciandos: uma experiência formativa no Sertão Nordestino. 2010; 193 F. Dissertação (Mestre)-Universidade Federal do Rio Grande do Norte, Natal, 2010.

NUNES, Sylvia; LOMÔNACO, José Fernando. Bitencourt. O aluno cego: preconceitos e potencialidades. Revista Semestral da Associação Brasileira de Psicologia Escolar e Educacional, São Paulo, v. 14, n. 1, p. 55-64; jan-jun. 2010.

OLIVEIRA, Marileide Antunes de; LEITE, Lúcia Pereira. Educação inclusiva: uma análise e intervenção em uma sala de recursos. Paidéia, Ribeirão Preto, v. 21, n. 49, 197-25, 2011.

PELIZZARI, Adriana. et al. Teoria da aprendizagem significativa segundo Ausubel. Revista PEC, Curitiba, v. 2, n.1, p. 37-42, jul. 2001- jul. 2002. 


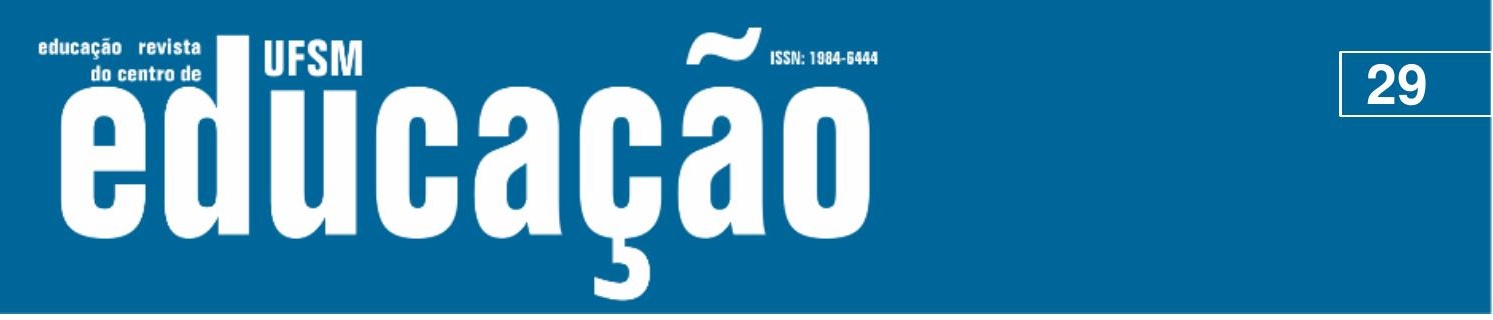

ISSN: 1984-6444 | http://dx.doi.org/10.5902/1984644445787

RAPOSO, Patrícia Neves; CARVALHO, Erenice Natalia S. de. A Pessoa com deficiência visual na escola. In: MACIEL, Diva Albuquerque Maciel; BARBATO, Silviane. (org.). Desenvolvimento humano, educação e inclusão escolar. 2. ed. Brasília: Editora UNB, 2010. p. 157-173.

RAZUCK, Renata Cardoso de Sá Ribeiro; GUIMARÃES, Loraine Borges. O desafio de ensinar modelos atômicos a alunos cegos e o processo de formação de professores. Revista Educação Especial, Santa Maria, v. 27, n. 48, p. 141-154, 2014.

RAZUCK, Renata Cardoso de Sá Ribeiro; OLIVEIRA NETO Washington de. A química orgânica acessibilizada por meio de kits de modelo molecular adaptados. Revista Educação Especial, Santa Maria, v. 28, n. 52, p. 473-486, 2015.

ROCHA, Telma Brito; MIRANDA, Theresinha Guimarães. A inclusão de alunos com deficiência no ensino superior: uma análise de seu acesso e permanência. In: DíAZ, Felix et al. (org.). Educação inclusiva, deficiência e contexto social: questões contemporâneas [online]. Salvador: EDUFBA, 2009, pp. 27-37.

SÁ, Marcio Gomes de; MOURA, Guilherme Lima. A crítica discente e a reflexão docente. Cadernos EBAPE.BR, Rio de Janeiro, v. 6, n. 4, p. 1-10, dez. 2008.

SANTOS, Allan Paulo Moreira dos et al. O processo de adaptação de livros didáticos e paradidáticos na inclusão de alunos cegos em escolas especiais e inclusivas. Revista Benjamin Constant, Rio de Janeiro, ano 20, edição especial, p. 48-57, nov. 2014.

SANTOS, Maria Jesus dos A escolarização do aluno com deficiência visual e sua experiência educacional. 2007. 113 F. Dissertação (Mestre em Educação) Universidade Federal da Bahia, Faculdade de Educação, Salvador, 2007.

SANTOS, Mônica Pereira dos; PAULINO, Marcos Moreira. Inclusão em educação: Culturas, políticas e práticas. São Paulo: Cortez, 2006.

SMITH, Corinne; STRICK, Lisa Dificuldades de aprendizagem de A a Z: um guia completo para país e educadores. Porto Alegre: Artmed Editora, 2001.

TRIVIÑOS, Augusto Nibaldo Silva. Introdução à pesquisa em ciências sociais: a pesquisa qualitativa em educação. São Paulo: Atlas,1987.

VIGINHESKI, Lúcia Virginia Mamcasz et al. O sistema braille e o ensino da matemática para as pessoas cegas. Ciência \& Educação, Bauru, v. 20, n. 4, p. 903916, 2014. 


\section{ussm \\ ISSN: 1984-6444

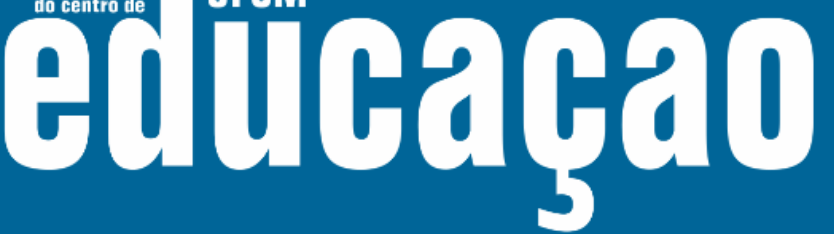

ISSN: 1984-6444 | http://dx.doi.org/10.5902/1984644445787

ZANI, Adriana Valongo; NOGUEIRA, Maria Suely. Incidentes críticos do processo ensino-aprendizagem do curso de graduação em enfermagem, segundo a percepção de alunos e docentes. Revista Latino-Americana de Enfermagem, Ribeirão Preto, v. 14, n. 5, p. set./out. 2006.

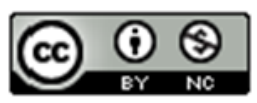

This work is licensed under a Creative Commons Attribution-NonCommercial 4.0 International (CC BY-NC 4.0) 